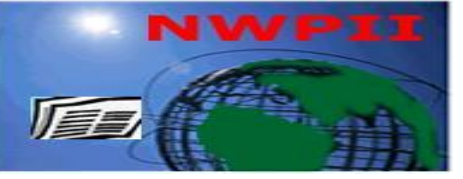

American Journal of Biomedical Sciences

ISSN: 1937-9080

nwpii.com/ajbms

\title{
Measurements of Surface Roughness in Conventional and Ultrasonically Assisted Bone Drilling
}

\author{
K. Alam*, A.V. Mitrofanov and V.V. Silberschmidt
}

Wolfson School of Mechanical and Manufacturing Engineering, Loughborough University, LE11 3TU, UK

*Corresponding author:

Khurshid Alam

Wolfson School of Mechanical and Manufacturing

Engineering, Loughborough University, LE11 3TU, UK

Tel: +44-1509-227534, Fax: +44-1509-227648

E-mail: k.alam2@lboro.ac.uk

Received: 26 March 2009; $\mid$ Revised: 25 May 2009; | Accepted: 2 June 2009

\begin{abstract}
Bone fracture due to an accident, aging or diseases is a feature of everyday life. One of the principal methods of repair and reconstruction of such a fracture is based on drilling the bone and fixing its separate parts together using screws, wires and plates. Morphology of the drilled hole surface and fixative components such as screws, pins and hooks influences strength of the bonds between them. Modern measurement methods provide researchers with a high-precision data on the main parameters of surface roughness. This study is concerned with measurements of surface roughness of holes drilled in a cortical bone using two drilling techniques. Hole's surface roughness produced with conventional drilling (CD) and ultrasonically assisted drilling (UAD) was measured with, and compared for, various contact and non-contact methods. The difference in surface roughness for both drilling techniques was explained based on high-speed filming of the bone drilling processes.
\end{abstract}

Keywords: Bone drilling; Ultrasonic vibrations; Surface profilometry; Experimental methods;

High-speed filming.

\section{Introduction}

Bone drilling is one of the major types of orthopaedic surgery and is frequently used to produce holes for inserting screws at required sites. Close tolerances and surface textures are critical for the osseointegration ability. The character of the surface affects the bone-screw interface strength as well as the cellular response, which is essential for early and healthy bone growth. Various techniques were employed to enhance bone apposition including bioactive coating and surface texturing of fixative components. Studies of surface roughening as a means of enhancing bone ingrowth have had encouraging results. There has been a continuing 
debate on the influence of implant surface topography on the success of operation. Internal fixation screws require a stable bone-implant interface for transmission of forces [1]. On the other hand, strong integration between the bone and screw is a disadvantage when considering removal of screws (especially in paediatric patients with fast growing bones), and the surface microstructure is the main determining factor here. Bony integration is minimized by using surfaces with minimal microstructure reducing the forces required to remove screws. Numerous studies investigated the effects of surface texture or microtopography on interfacial strength and the cellular response, both in vivo and in vitro (see e.g. [2-7]).

Presently, a mechanical rotary drill is the main type of drilling equipment used in clinical practices. Various drilling techniques have been introduced to improve the process in order to minimise the invasiveness of the operation. One of such modern drilling techniques utilises highfrequency, ultrasonic vibration of the drill along its longitudinal axis and is called ultrasonically assisted drilling (UAD). Ultrasonic vibration has been already successfully applied on a wide scale in cutting high-strength aerospace alloys [8], composites [9] and soft materials [10]. Ultrasonically assisted surgical instruments for cutting bones and removing the periosteum are becoming popular in orthopaedic, neuro and dental surgeries [11]. In medical applications an ultrasonic tool can reduce cutting forces and provide a surgeon with better control to cut the bone tissue [12].

Previous research was mainly concerned with the measurement of implant's surface topography in relation to anchoring to the bone. To authors' knowledge, there is no study reported so far describing the bone hole surface roughness produced with either $\mathrm{CD}$ or UAD. Evaluation of the contact between the bone and fixative components (i.e. screws or pins) that takes into account the bone surface roughness would allow a more precise analysis tools to be built. It is also envisaged that an experimental study will be conducted in the future to investigate the influence of the bone surface roughness on the fixation strength. The present study is aimed at measurement of the average roughness of the drilled hole surface, which is by far the most extensively used surface parameter. High-speed filming of bone drilling processes was performed to visualise the mechanism of the chip formation that affects surface quality.

\section{Materials and Methods}

\subsection{Specimen preparation for drilling}

In our study drilling tests were carried out on bovine femur. This bone is of most interest as it is the closest animal bone to replicate the characteristics of human bone [13]. The bone was obtained from a local butcher where it had been boned (meat removed) and was stored frozen at $10^{\circ} \mathrm{C}$ before the experiment. Periosteum was removed from the outer surface of the bone specimen as it causes the drill flutes to clog [14]. Epiphysis was removed and the mid-diaphysis columns were obtained using a hacksaw as shown in Figure 1. The average thickness of the cortical wall was $8 \mathrm{~mm}$. The specimens were visually free from any significant osteopenia and musculoskeletal disease.

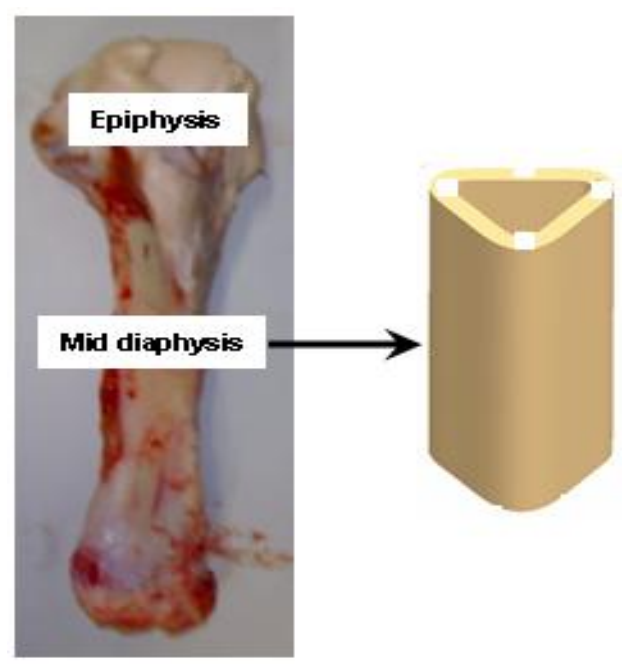

Figure 1. Fresh bovine bone (a) and its sample cut from mid-diaphysis (b).

\subsection{Experimental apparatus for drilling}

A conventional lathe machine with a standard twist drill was employed in these experiments (see Figure 2a). In UAD the drill was connected to the horn (concentrator) and transducer of the 
ultrasonic device. An ultrasonic transducer was designed with two piezoelectric plates positioned (fixed) between two non-piezoelectric materials. Piezoelectric plates created dynamic stress waves when subjected to an AC current. This vibration was channelled to the tip of the drill. A special mounting system was used to hold, rise and lower the specimen whilst drilling at various locations. The schematic of the ultrasonic system is shown in Figure 2b.
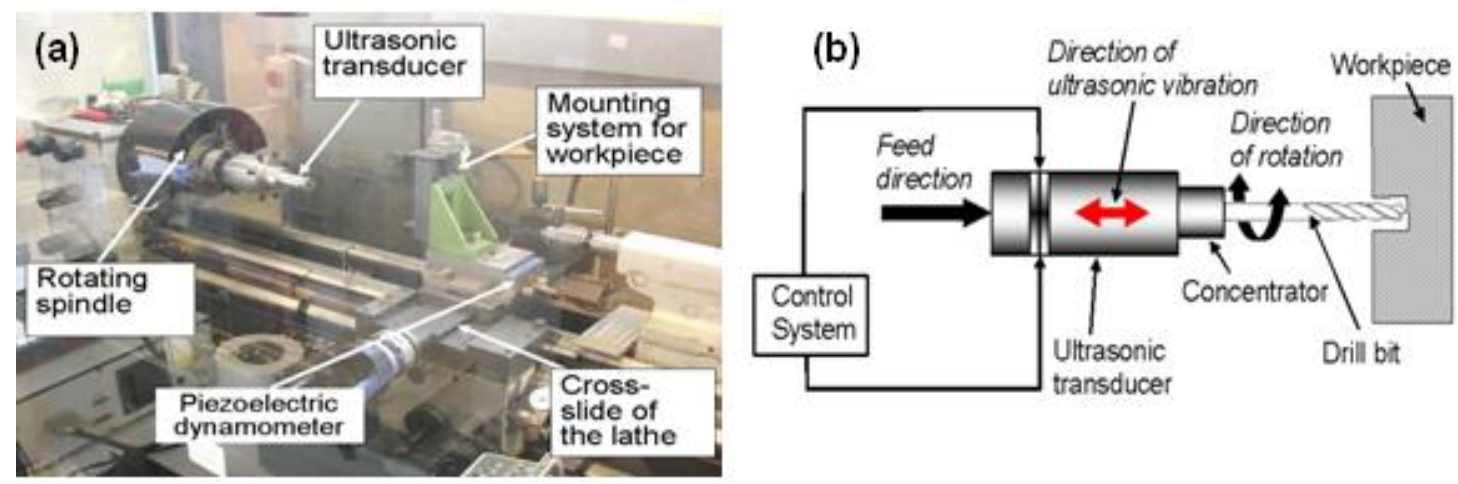

Figure 2. Experimental setup for drilling: (a) drilling equipment; (b) schematic of ultrasonic device.

\subsection{Non-contact roughness measurement}

Surface roughness is the measure of fine surface irregularities in the surface texture. These are the result of the manufacturing processes employed to create the surface. Surface roughness parameter $\left(R_{a}\right)$ is rated as the arithmetic average deviation of the surface valleys and peaks expressed in microinches or micrometers. Two different methods were used to characterise roughness of surfaces of drilled bones. The Talysurf CLI 2000 system was used in our noncontact analysis; this is a scanning topography measurement instrument (experimental arrangement is shown in Figure 3). It means that the gauge measures the altitude of only one point at a time, and the study sample is moved on the cross-slides in order to scan the complete measurement area. Confocal point gauge 300 based on chromatic length aberration (CLA) principle was used due to high resolution measurement. In this technique a white light is directed by a beam splitter through a spectral aberration lens onto the surface. The lens splits the light into different wavelengths and at any point on the surface only a certain wavelength is focused. Light is reflected from the surface to a pin hole, which permits only the wavelength in focus to pass through. A spectrometer deflects the light onto a CCD sensor to interpolate the spatial Am. J. Biomed. Sci. 2009, 1(4), 312-320; doi: 10.5099/aj090400312 position of the data point. The instrument can scan areas up to $200 \mathrm{~mm} \times 200 \mathrm{~mm}$ with maximum measurement speed $30 \mathrm{~mm} / \mathrm{sec}$. The specifics of this test in measuring bone surface roughness will be given in the section with results.

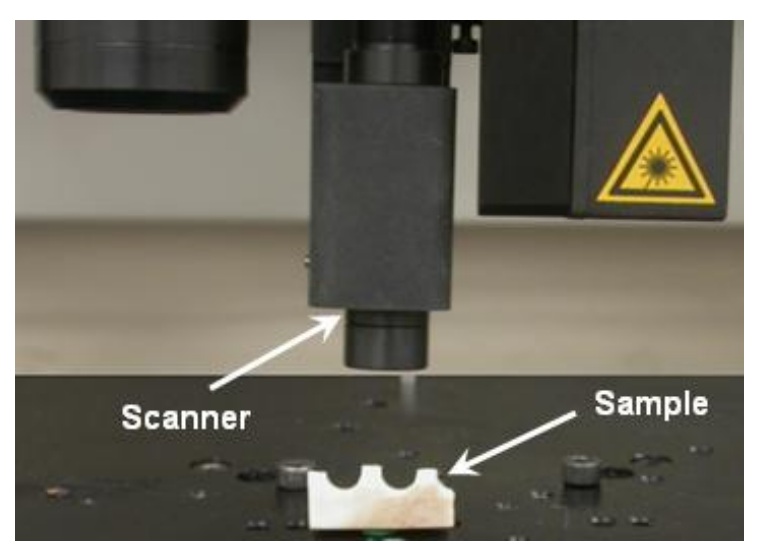

Figure 3. Experimental setup for surface roughness analysis (Talysurf CLI 2000)

\subsection{Contact roughness measurement}

The Talysurf 4 system was employed in contact measurements of roughness of drilled holes. It is a surface texture measuring instrument with a stylus traversed across the surface; its vertical movement is converted into an electrical signal. The $R_{a}$ value is derived from the filtered (C) 2009 by NWPII. All rights reserved. 
signal and is displayed on either a pointer or digital type meter. The pick-up used in Talysurf 4 is based on a variable position-sensitive inductance, with a signal proportional to the displacement, even when the stylus is stationary. Styluses of various sizes can be fit on the system to handle a variety of sample sizes and shapes. The experimental set up and specimen fixation in our tests are shown in Figure 4.

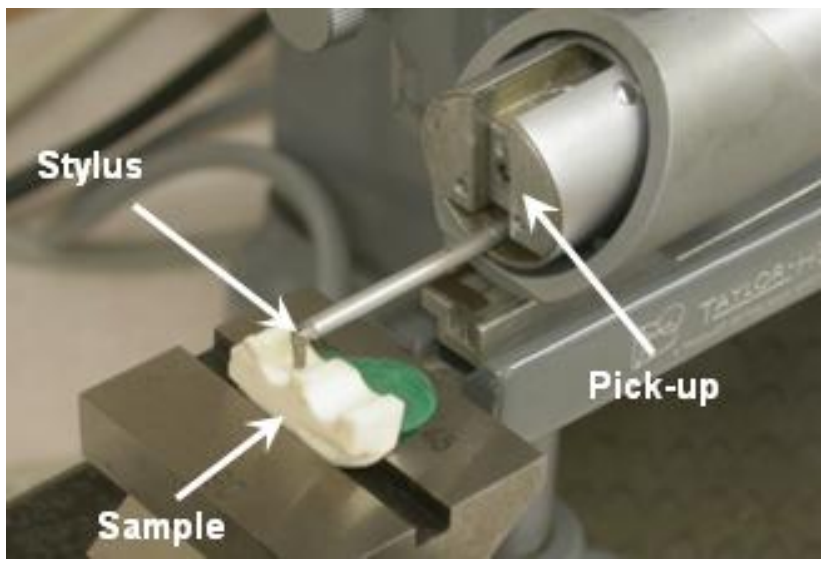

Figure 4. Experimental setup for surface roughness measurement using Talysurf 4

\subsection{Experimental procedure}

Ten holes were drilled with each drilling technique - CD and UAD. The drilling speed and drill diameter used in the experiments (see Table 1) were chosen according to the data widely reported in literature for bone drilling [15-16]. The feed rate and drilling speed were kept constant throughout the experiments. Drilling was performed in a direction perpendicular to the cortical wall and the bone axis. After drilling the parts of the bones with holes were cut with a hacksaw along the axis of the bone (line $A B$ in Figure 5) to provide an access to the formed surfaces for measurements. Test samples each containing two holes drilled with $\mathrm{CD}$ and UAD, respectively, were then cut off from the original sample for examination. The edges of the samples were polished to remove burrs thus leaving $6 \mathrm{~mm}$ hole depth for examination.

The $R_{a}$ values were measured using two techniques: (1) surface scans from a distance, and (2) contact measurements, with the measuring instrument was in direct contact with the hole surface. In a non-contact method the amplitude for the points of 2D profile of the surface was captured with the CLA transducer (resolution of $0.02 \mathrm{~nm})$. The spatial resolution for the stage movement was $0.5 \mu \mathrm{m}$ beneath the CLA gauge. The specimens were taken for surface examinations immediately after drilling to avoid the effect of drying. The surface roughness measurements of the hole surface were taken along the axis of the drilled hole (line EF in Figure $5)$. The surface roughness was calculated using the relation

$$
R_{a}=\frac{1}{L} \int_{0}^{L}|f(x)| d x
$$

where $L, z, x$ are the evaluation length, height and the distance along measurement, respectively.

The next section describes the results of these measurements.

Table 1. Drilling parameters used in experiments

\begin{tabular}{lcc}
\hline \multicolumn{1}{c}{ Parameters } & CD & UAD \\
\hline Drilling speed $(\mathrm{rpm})$ & 2000 & 2000 \\
Drill diameter $(\mathrm{mm})$ & 4 & 4 \\
Feed rate $(\mathrm{mm} / \mathrm{min})$ & 40 & 40 \\
Vibration amplitude $(\mu \mathrm{m})$ & N/A & 10 \\
Vibration frequency $(\mathrm{kHz})$ & N/A & 20 \\
\hline
\end{tabular}

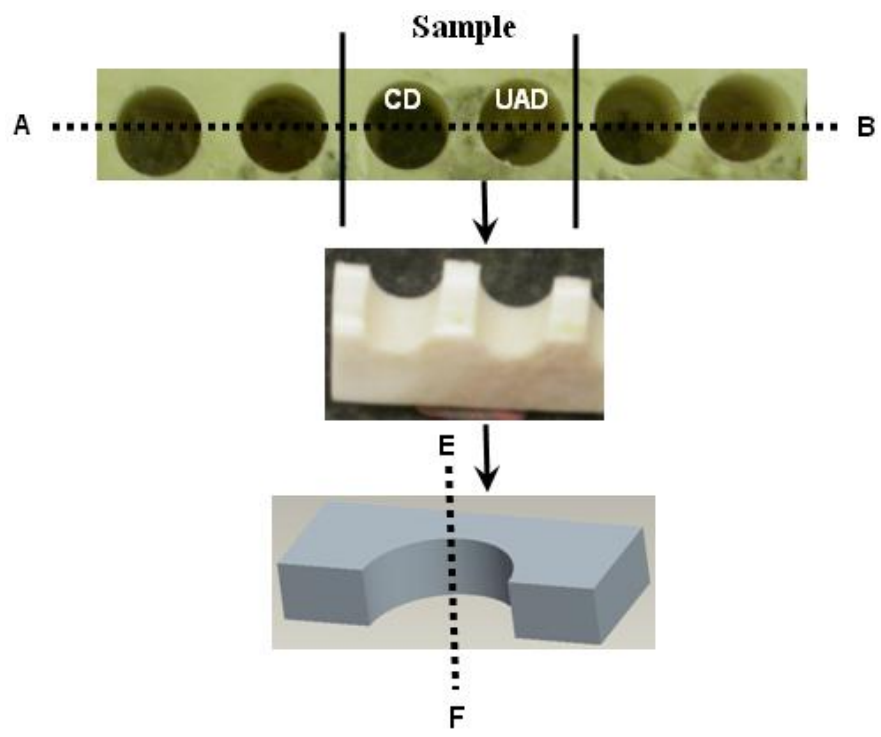

Figure 5. Stages in sample preparation and direction for roughness measurements. 


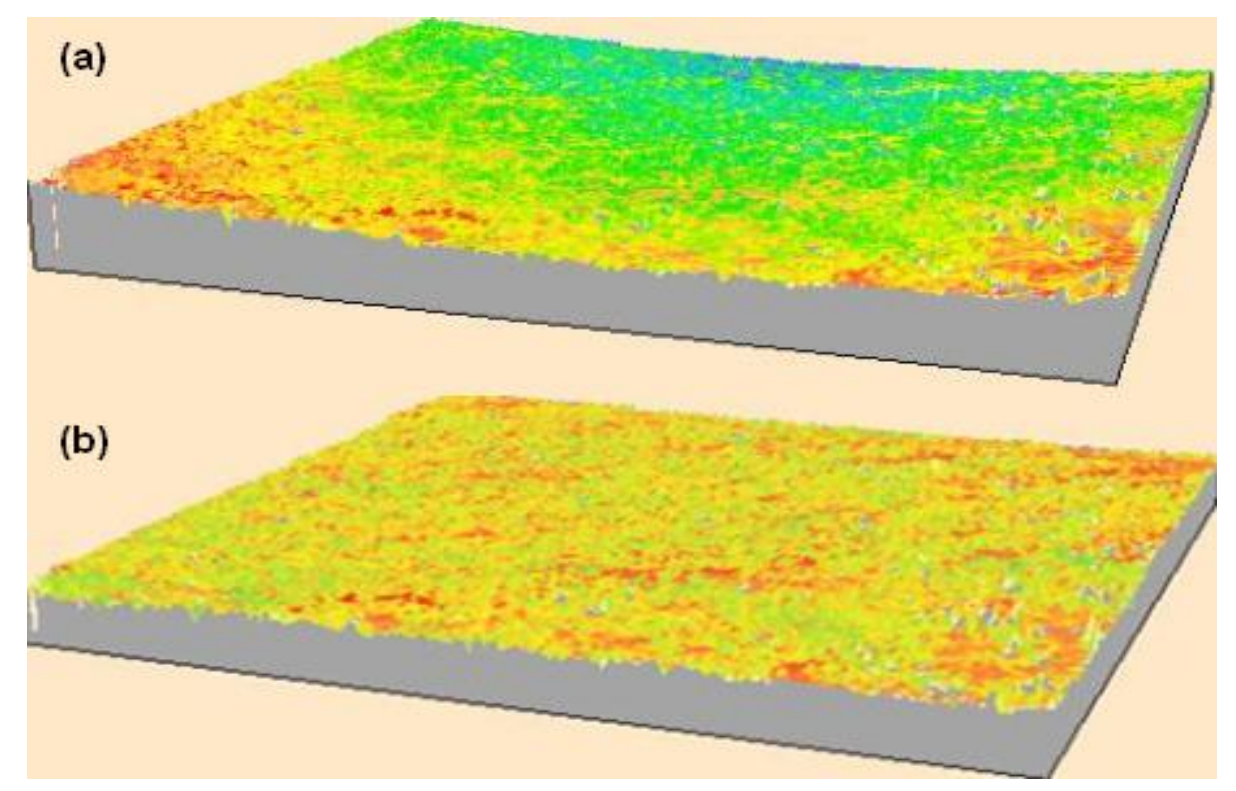

Figure 6. Oblique views showing roughness details on the surface obtained using Talysurf CLI 2000 with cylindrical effect (a) and after cylindrical effect was removed (b). Scanned area $6 \mathrm{~mm} \times 4 \mathrm{~mm}$

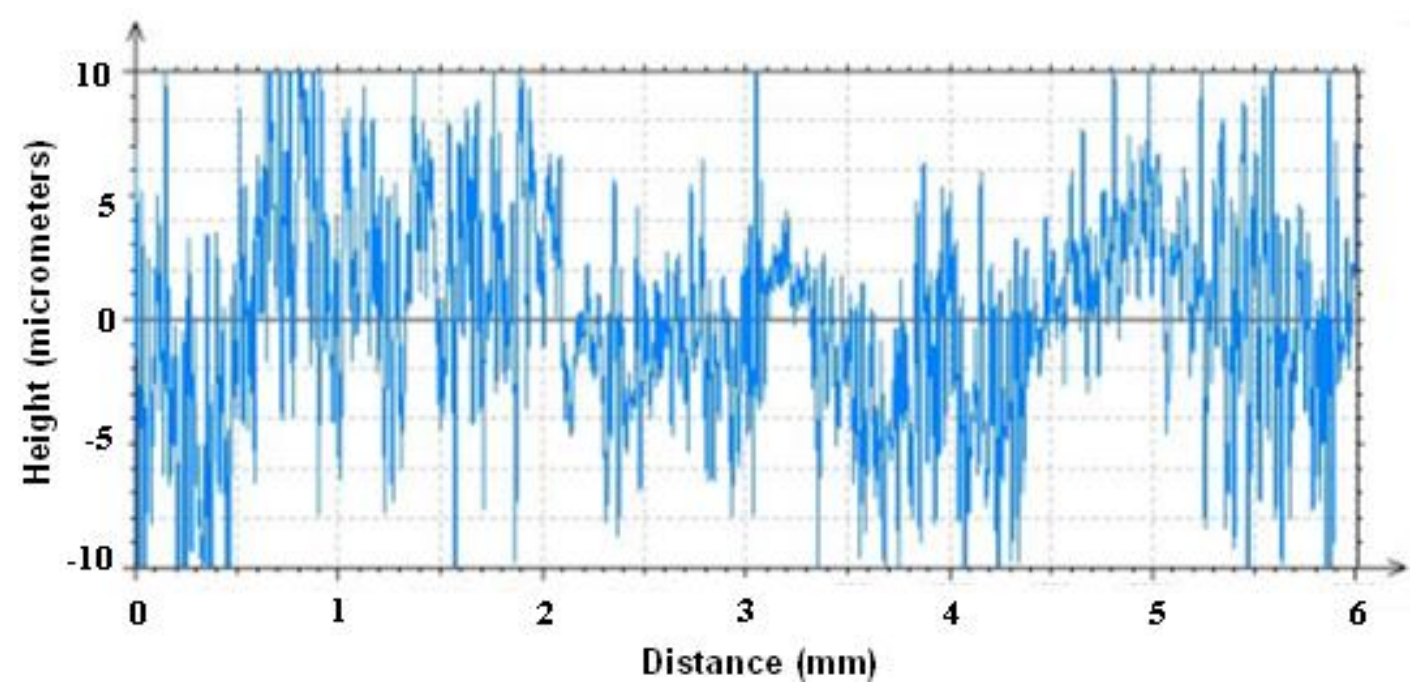

Figure 7. Roughness pattern obtained with Talysurf CLI 2000 along hole depth

\section{Results}

\subsection{Non-contact method}

Bone samples were mounted on the crossslides of the Talysurf CLI 2000 instrument. The scanning speed was kept at $0.5 \mathrm{~mm} / \mathrm{s}$. The instrument scanned an area of $6 \mathrm{~mm} \times 4 \mathrm{~mm}$ along the entire hole depth. The distance between the sample and scanner was found approximately 6 $\mathrm{cm}$ to achieve better surface intensity for measurements. The scanned images were analysed using TalyMap software. An oblique plot of the scanned area is shown in Figure 6. The software has the capability to remove the cylindrical effect from the scanned area and converting it into a flat one for measurement purposes. A typical surface profile obtained with Talysurf CLI 2000 is shown in Figure 7 while Figure 8 provides a comparison of $R_{a}$ values for CD and UAD. The average levels of $R_{a}$ for 10 holes drilled with $\mathrm{CD}$ and UAD were 
$1.52 \mu \mathrm{m}$ and $1.35 \mu \mathrm{m}$, respectively. It means that the hole surface obtained with $\mathrm{CD}$ was rougher than that drilled with UAD.

\subsection{Contact method}

The non-contact method applied required a sufficiently reflective surface for accurate measurements [17]. The measured bone surface was light in colour, and it was very hard to focus on it for examination. Hence, to validate the results obtained with the non-contact method described above, the contact method was also used. In that method, a physical contact between the surface and a measuring probe (stylus) was achieved. The sample was carefully mounted on the stage of Talysurf 4 . The stylus was moved over the surface with a speed of $10 \mathrm{~mm} / \mathrm{min}$. A typical surface profile obtained with Talysurf 4 is shown in Figure 9; a comparison of measured $R_{a}$ values for CD and UAD is given in Figure 10 .

The average $R_{a}$ values for 10 bone specimens drilled with $\mathrm{CD}$ and $\mathrm{UAD}$ was $1.37 \mu \mathrm{m}$ and 1.28 $\mu \mathrm{m}$, respectively. Those values are in a good agreement with the magnitudes provided by the non-contact method.

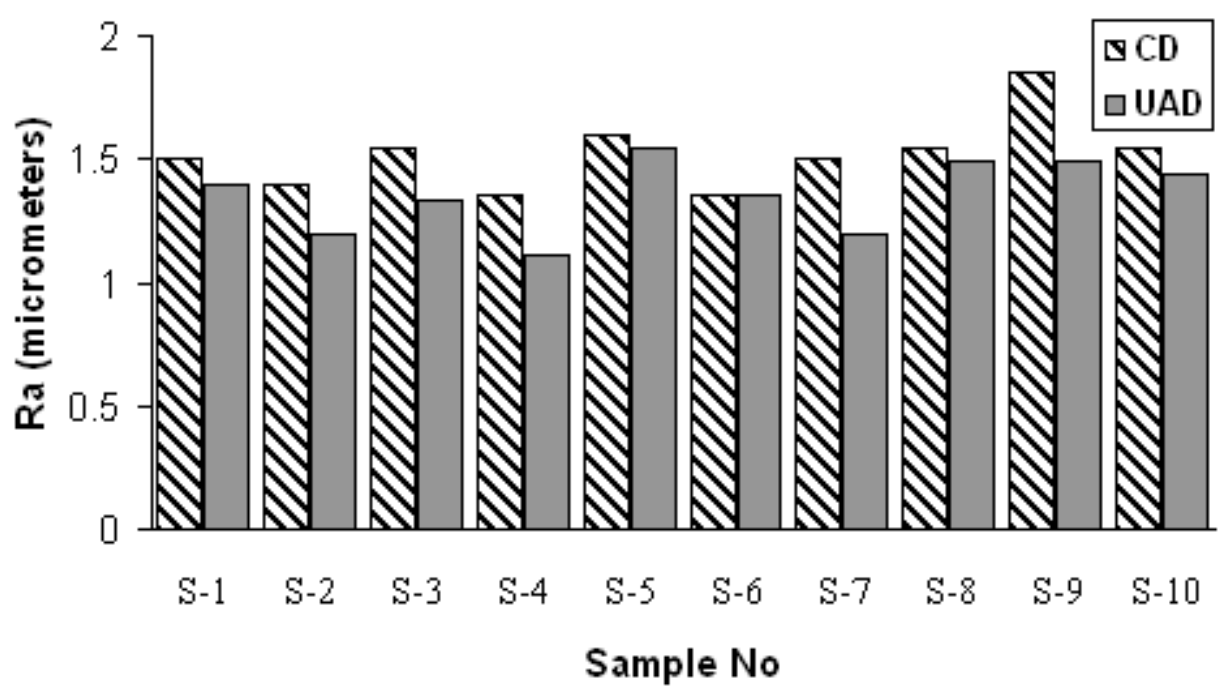

Figure 8. Comparison of roughness parameter $R_{a}$ of hole surface using Talysurf CLI 2000. Each bar graph for each sample represents the mean of five scans

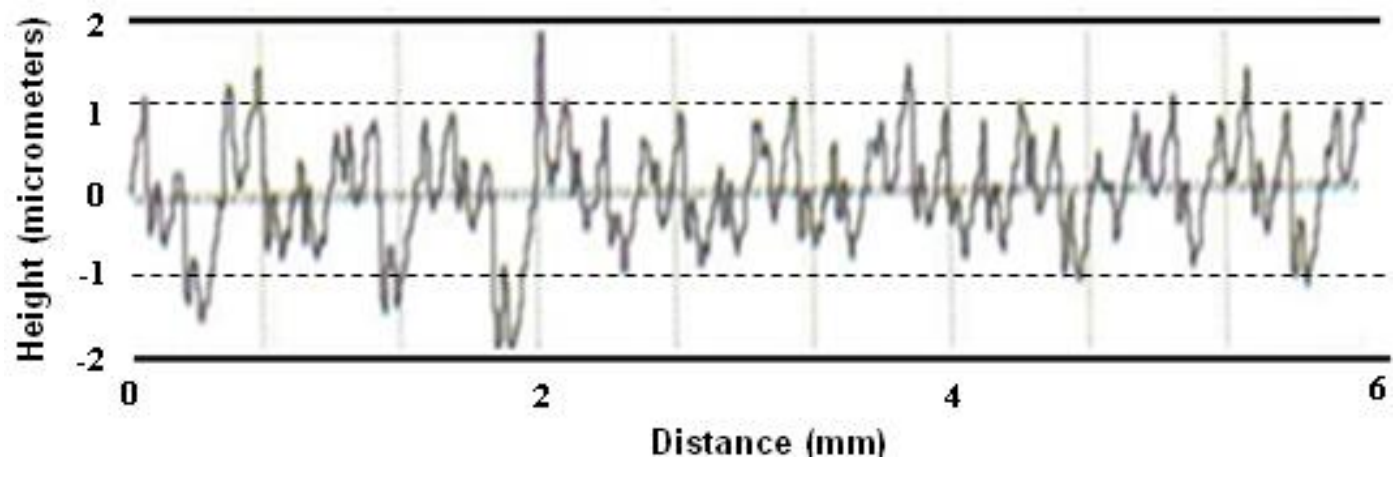

Figure 9. Roughness pattern obtained with Talysurf 4 along hole depth 


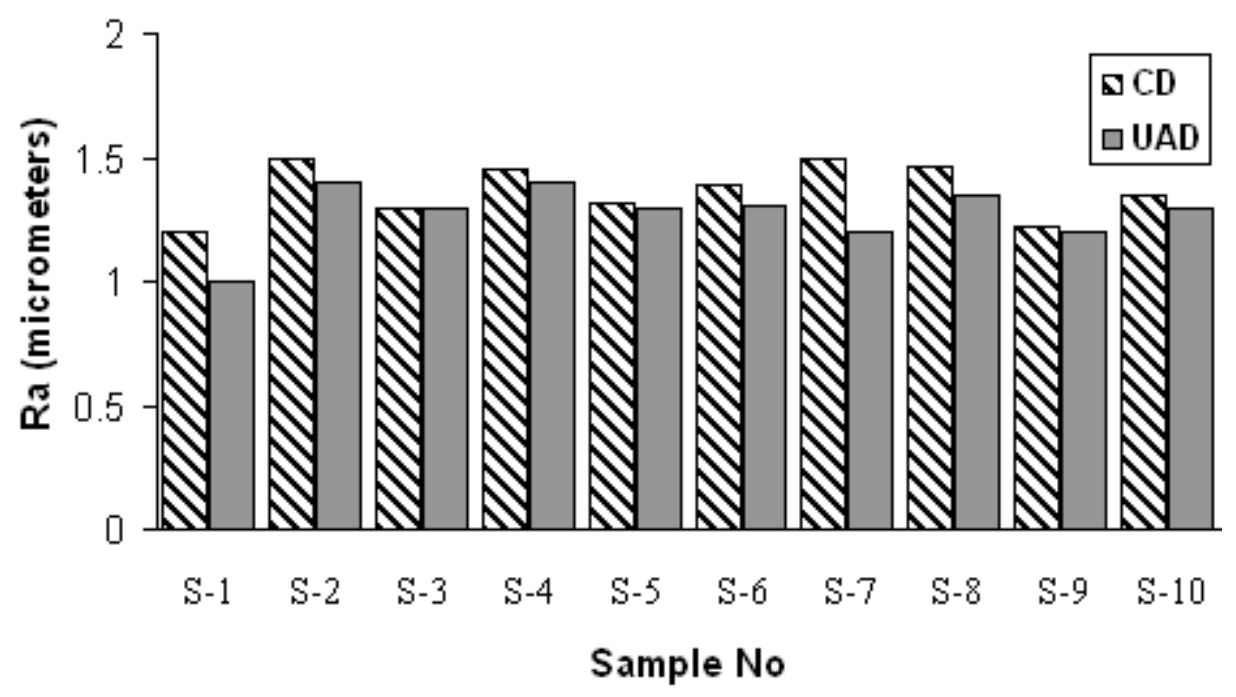

Figure 10. Comparison of roughness parameter $R_{a}$ values of hole surface using Talysurf 4. Each bar graph of each sample represents the mean of five measurements
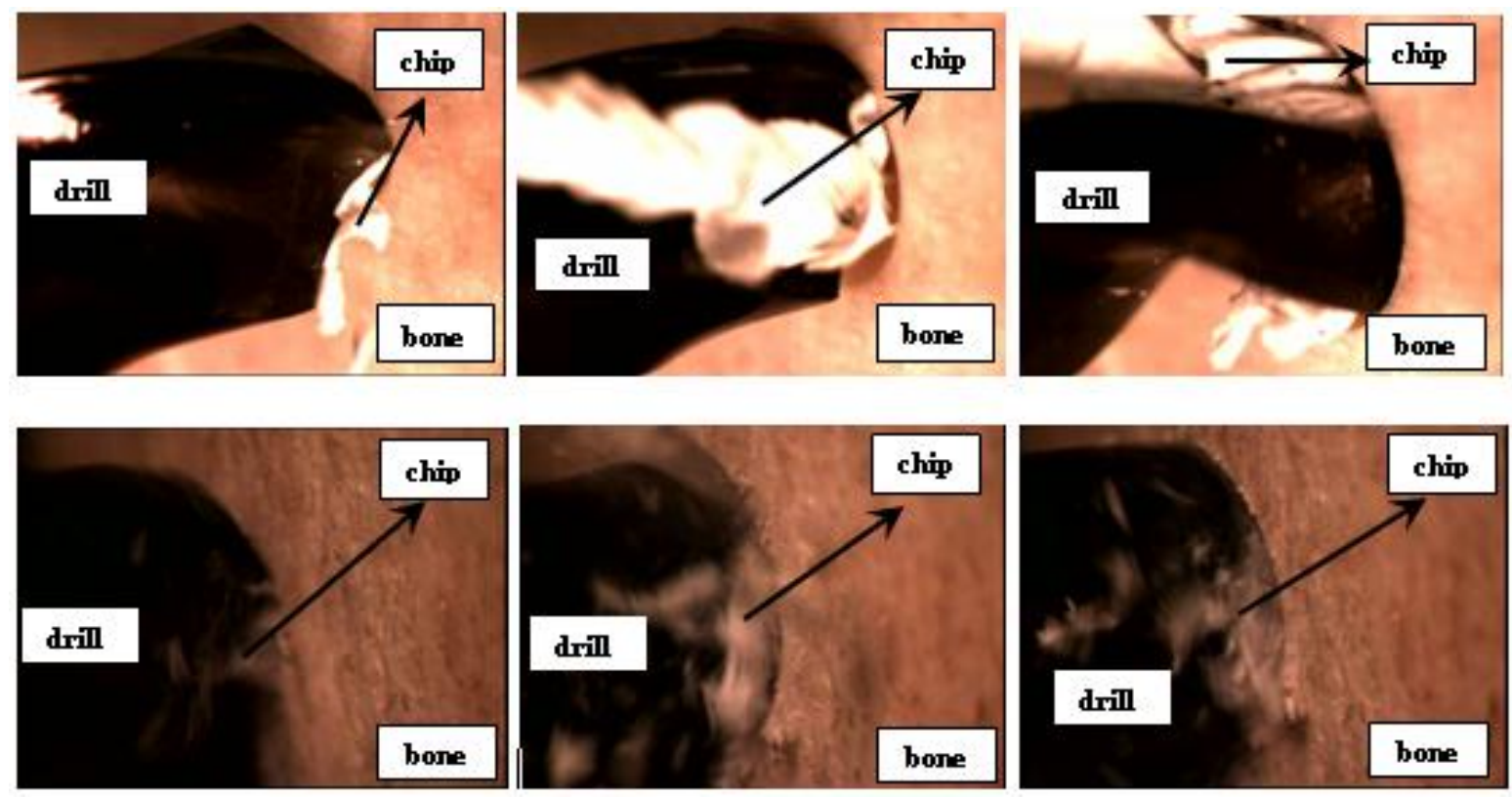

Figure 11. Images obtained with high-speed filming showing chip formation in drilling fresh bone with two drilling techniques. First row - CD, second row - UAD. Left column - initial engagement of drill lips; middle column - half-lip engagement; right column - full lip engagement.

\section{Chip formation in bone drilling}

The effect of drilling technique on quality of the hole surface may be explained by observing the process of bone drilling. To study the interaction between the bone and the drilling tool, chip formation mechanisms were studied using high-speed filming of the drilling process. The main stages of these processes are presented in Figure 11.

It was observed that $\mathrm{CD}$ produced spiral cone chips while UAD produced needle-shaped chips. In $\mathrm{CD}$ the chips were seen rotating along the drill bit rubbing against the hole surface and blocking Am. J. Biomed. Sci. 2009, 1(4), 312-320; doi: 10.5099/aj090400312 @ 2009 by NWPII. All rights reserved. 
the flutes. UAD was observed to produce broken chips and no rubbing of the chips was seen against the hole surface. The spiral chips are reported to cause higher specific cutting energy and rough hole surfaces in drilling [18]. Based on these observations, it was concluded that the surface roughness produced by UAD was lower than that in $\mathrm{CD}$, which was consistent with surface roughness results described in Section 3.

\section{Conclusions}

The levels of surface roughness of holes drilled in the bovine cortical bone using two drilling techniques were measured. The surface texture indicated that the hole surface produced by ultrasonically assisted drilling (UAD) was somewhat smoother than that obtained with conventional drilling (CD). The difference in roughness was about $6.5 \%$ as measured with the contact method and $11 \%$ with the non-contact one.

The values of $R_{a}$ obtained with both measurement methods were in a good agreement. Hence, non-contact methods may be confidently applied to measure the surface quality of bone tissues. The non-contact method was relatively quick and handled relatively larger areas. Lower surface roughness produced in UAD may be attributed to an improved chip removal from the drilling site. A rough surface may be achieved using $\mathrm{CD}$, which will provide better anchorage of bone tissue to the implants and fixing screws. For a reduced drill penetration force and improved chip removal to avoid flutes blocking and risk of drill breakage, UAD would be a better choice. Further research is needed to evaluate the integrity of the drilled hole surface, in order to ensure the interfacial strength is not affected. The selection of the optimum drilling technique for clinical practices is a complex matter and depends strongly on the objectives of the operation.

\section{Acknowledgements}

The authors wish to acknowledge the help provided by Mr. Jagpal Singh in the experiments.

\section{References}

1. Richards, R.G. Surfaces to control implant tissue adhesion for osteosynthesis, Folia Traumatologica Lovaniensia, Reynders, P., Burssens, P., Bellemans, J., Broos, P., Ed.; KU Leuven, 2007, p.15.

2. Larsson, C.; Thomsen, P.; Lausmaa, J.; Rodahl, M.; Kasemo, B.; Ericson, L.E. Bone response to surface modified titanium implants: studies on electropolished implants with different oxide thicknesses and morphology, Biomaterials, 1994, 15(13), 1062-1074.

3. Chang, C.K.; Wu, J.S.; Mao, D.L.; Ding, C.X. Mechanical and histological evaluations of hydroxyapatite-coated and noncoated Ti6Al4V implants in tibia bone, Journal of Biomedical Materials Research A, 2001, 56(1), 17 - 23.

4. Hansson, S.; Norton, M. The relation between surface roughness and interfacial shear strength for bone anchored implants. A mathematical model, Journal of Biomechanics, 1999, 32, 829-836.

5. Martin, J.Y.; Schwartz, Z.; Hummert, T.W.; Schraub, D.M.; Simpson, J.; Lankford, J. Jr.; Dean, D.D.; Cochran, D.L.; Boyan, B.D. Effect of titanium surface roughness on proliferation, differentiation, and protein synthesis of human osteoblast-like cells (MG63), Journal of Biomedical Material Research A, 1999, 29(3), 389-401.

6. Michaels, C.; Keller, J.; Stanford, C.; Solursh, M. In vitro cell attachment of osteoblast-like cells to titanium, Journal of Dental Research, 1989, 68, 276-281.

7. Pearce, A.I.; Pearce, S.G.; Schwieger, K.; Milz, S.; Schneider, E.; Archer, C.W.; Richards, R.G. Effect of surface topography on removal of cortical bone screws in a novel sheep model, Journal of Orthopaedic Research, 2008, 26(10),1377-1383.

8. Mitrofanov, A.V.; Babitsky, V.I.; Silberschmidt, V.V. Thermomechanical finite element simulations of ultrasonically assisted turning, Computational Materials Science, 2005, 32, 463-471.

9. Li, Z.C.; Jiao, Y.; Deines, T.W.; Pei, Z.J.; Treadwell, C. Rotary ultrasonic machining of 
ceramic matrix composites: feasibility study and designed experiments, International Journal of Machine Tools and Manufacture, 2005, 45, 1402-1411.

10. Lucas, M.; MacBeath, A.; McCulloch, E.; Cardoni, A. A finite element model for ultrasonic cutting, Ultrasonics, 2006, 44, 503509.

11. Krause, W. R. Orthopaedic cutting procedures, BONEZone, 2003, 2, 4-10.

12. Khambay, B.S.; Walmsley, A.D. Investigations into the use of an ultrasonic chisel to cut bone. Part 2: Cutting ability, Journal of Dentistry, 2000, 28, 39-44.

13. Vashishth, D.; Tanner, K.E.; Bonfield, W. Contribution, development and morphology of microcracking in cortical bone during crack propagation, Journal of Biomechanics, 2000, 33, 1169-1174.

14. Jacob, C.H.; Berry, J.T.; Pope, M.H.; Hoagland, F.T. A study of bone machining process, Journal of Biomechanical Engineering, 1976, 9, 343-349.

15. Hillery, M.T.; Shuaib, I. Temperature effects in the drilling of human and bovine bone, Journal of Materials Processing and Technology, 1999, 92-93, 302-308.

16. Bachus, K.N.; Rondina, M.T.; Hutchinson, D.T. The effects of drilling force on cortical temperatures and their duration: an in vitro study, Medical Engineering and Physics, 2000, 22(10), 685-691.

17. Wallace, R.J.; Whitters, C.J.; McGeough, J.A.; Muir, A. Experimental evaluation of laser cutting of bone, Journal of Materials Processing Technology, 2004, 149, 557-560.

18. Batzer, S.A.; Haan, D.M.; Rao, P.D.; Olson, W.W.; Sutherland, J.W.. Chip morphology and hole surface texture in the drilling of cast Aluminum alloys, Journal of Materials Processing Technology, 1998, 79, 72-78. 